\title{
Microbial Decontamination of Fuel Tanks as a Mechanism of the Motion of an Aircraft through MIRCE Space
}

\author{
J Knezevic* \\ MIRCE Akademy, Woodbury Park UK
}

*Corresponding author: J Knezevic, MIRCE Akademy, Woodbury Park, Exeter, UK.

Received Date: October 12, 2020

Published Date: November 05, 2020

\begin{abstract}
The paper addresses the microbial decontamination of fuel tanks as a physical mechanism of the motion of an aircraft through MIRCE Space, in accordance with MIRCE Science ${ }^{1}$. In cases where microbiological contamination is detected and decontamination needs to be done with biocides, up-to-date instructions in the Aircraft Maintenance Manuals should be followed to ensure that the correct method and dosage is applied. Although in-service problems with this maintenance task are not frequent, the consequences of its incorrect execution could lead to the occurrence of "a serious incident". The case study analysed in this paper is related to the event of this type that took place at London Gatwick Airport on 26 February 2020. A full understanding of the sequence of actions that led to the occurrence of this negative functionability event is essential for drawing recommendations for the reduction of the probability of human errors during the microbial decontamination process of fuel tanks of an aircraft, some on which are presented in this paper.
\end{abstract}

\section{Introduction}

Millions of gallons of aviation turbine fuel are used daily to power thousands of the aircraft to facilitate thousands of flights all over the world. It is complex mixture of thousands of organic compounds known as hydrocarbons, which is sterile when produced. However, during the transport, storage and in the aircraft fuel tank, it may become contaminated. One of the major contaminants of aviation fuel are microbes, like bacteria and fungi. Contaminated fuel can cause significant damage to the aircraft and engine, which can range from fuel system corrosion, clogging of fuel filtration components, failure of aircraft fuel system instrumentation, and even stopping the fuel supply to the engines during flight and in some cases may even be fatal. In the past several aeroplane crashes have been attributed to the deterioration of aviation fuel caused by microbial contamination [2].
Microbial contamination is not specific to any one fuel type, diesel, petrol, biodiesel, kerosene, gasoline, and other fuels used in marine, aviation, automotive and home heating applications are all susceptible. Similarly, there is no single specific organism that can be identified as being responsible for degradation and spoilage. As a general rule, wherever fuel and water come into contact in storage or distribution system microbial contamination is likely to occur. In the initial stages of contamination, the organisms present are predominantly aerobic, using the dissolved oxygen in the water for respiration. As this supply of oxygen is depleted, anaerobic organisms, known as sulphate reducing bacteria, develop. These organisms do not require oxygen for respiration and form corrosive waste products such as hydrogen sulphide. Once a microbial population becomes established fuel quality rapidly deteriorates.

\footnotetext{
1.MIRCE Science is a body of knowledge that studies the motion of functionable systems through MIRCE Space resulting from any functionability actions whatsoever and predicts work done and resources needed.[1]
} 
Problems such as haziness, failure to meet specifications, corrosion, filter plugging, and additive degradation can occur. All of these problems are related directly to the presence of microorganisms or their associated by-products. Several factors that affect the presence of microbial contaminants in jet fuel and thus determine to a large extent the quality of aviation fuel, have been determined. Among them, as indicated by numerous studies, the presence of free water is the most important one. However, for various reasons it is almost impossible to prevent the presence of at least minimal amounts of water in jet fuel. Therefore, microbial contamination of turbine fuel is almost inevitable, which requires decontamination actions to take place in order to restore the functionability of the aircraft affected. The main objective of this paper is to address microbial decontamination of fuel tanks as a potential mechanism of the motion of an aircraft though MIRCE Space, which could have a huge impact on its physically measurable functionability performance, namely work done and resources consumed. Also, based on the real-life case study analyzed in the paper possible recommendations for the reduction of the probability of human error during the microbial decontamination of fuel tanks are presented, based on the philosophy of MIRCE Science.

\section{MIRCE Science Fundamentals}

The philosophy of MIRCE Science is based on the premise that the purpose of existence of any functionable system ${ }^{2}$ is to do a work, which is considered to be done when a measurable function is delivered through time, like miles travelled, units produced, energy supplied and similar [1].

According to MIRCE Science, at any instant of calendar time, a given functionable system ${ }^{2}$ could be in one of the following two states [1]:

- $\quad$ Positive Functionability State (PFS), a generic name for a state in which a functionable system is able to deliver the expected measurable function(s),

- $\quad$ Negative Functionability State (NFS), a generic name for a state in which a functionable system is unable to deliver the expected measurable function(s), resulting from any reason whatsoever.

In MIRCE Science a functionability performance of a functionable system is defined by the trajectory of its motion thorough MIRCE Space. Mathematically, it is a three-dimensional space containing functionability points, each representing a discrete functionability state that a functionable system could be found in, probability of being in each of these states along the continuous calendar time.

The motion of a functionable system through the MIRCE Space is generated by functionability actions, which are classified as:
- $\quad$ Positive Functionability Action (PFA), a generic name for any cause whatsoever that compels a system to move to a PFS.

- $\quad$ Negative Functionability Action (NFA), a generic name for any cause whatsoever that compels a system to move to a NFS.

MIRCE Mechanics is a part of MIRCE Science that focuses on the scientific understanding of the mechanisms that generate functionability actions that govern the motion of functionable systems though MIRCE Space [1]. A full understanding of these mechanisms is essential for predicting the expected functionability performances using MIRCE Science Equation, like work done and resources consumed.

\section{Microbial Contamination Treatment and Preven- tion}

Microorganisms that grow in water and use the hydrocarbons from the fuel as a food cause microbiological contamination of fuel in fuel tanks. The most effective means to prevent this contamination is protection of water ingress and accumulation in the fuel tanks is. Thus, keeping fuel tanks clean is one of the best methods to avoid contamination.

Preventive actions against microbial contaminations of fuel tanks can be considered as the following three parts: ${ }^{3}$

- $\quad$ Fuel monitoring program for the microbes that consists of a periodic testing and sampling of the fuel. The main objective is to minimise the problems by early detection of microbial growth. During this process the procedures that are outlined in appropriate industrial standards and aircraft manufacturer's maintenance manuals should be followed.

- Maintenance of fuel system whose main objective is to prevent microbial growth in fuel by reducing the exposure of the fuel to water. There are various ways this could be achieved [2].

- $\quad$ Fuel treatment methods that should control the spreading of microbial growth including decontamination, which is a removal of the already developed biomass or the sludge. When choosing a remover, several factors should be considered namely the solubility of the fuel/water, compatibility with system components, compatibility with fuel and other additives, speed desired to eliminate the microbes, in accordance to regulatory approvals.

In this paper a highly effective "shock dosage" (killing existing growth) microbial decontamination process will be examined and analysed.

\footnotetext{
2. Functionable system is a set of mutually related entities that delivers a physically measurable work through a calendar time in accordance to operationally defined rules. [1]

${ }^{3}$ https://fuelandfriction.com/trucking-pro/microbial-growth-in-fuel-prevent/\#: :text=\%E2\%80\%9C\%20Fuel\%20tanks\%20and\%20other\%20
} storage $\% 20$ systems $\% 20$ are,can\%20also $\% 20$ cause $\% 20$ tank\%20 corrosion $\% 20$ and $\% 20$ fuel $\% 20$ spoiling (accessed 5.8.2020) 


\section{Microbial decontamination}

In case microbiological contamination is detected and needs to be treated with biocides, maintenance personnel, aircraft owners and operators are expected to follow up-to-date instructions in the engine and aircraft manufacturer's Aircraft Maintenance Manuals (AMMs) to ensure that the correct method and dosage is applied during the decontamination process.

In case of discrepancies caused by different update cycles of aircraft documentation, it is imperative that the manufacturer should be contacted for further advice.

During the microbial decontamination process appropriate precautions should be taken, which include the following:

- $\quad$ Personal protection equipment (PPE) should be employed to avoid dermal contact, including suitable gloves of butyl rubber or nitrite rubber, safety goggles, and if required, a face shield.

- $\quad$ Treated fuel tanks should be at least $10 \%$ full before treatment. Do not dispense into empty fuel tanks

- Used biocides must be treated in accordance to local regulatory requirements and must not exceed recommended dose levels ${ }^{3}$

- $\quad$ The most reliable way to get additive into the fuel system is by metered injection. If the use of an injection system is not possible a batch may be made to pre-dilute the product

\section{The biocides}

Harmful or unwanted organisms such as viruses, bacteria, fungi, insects and animals are controlled by biocides through chemical or biological means.

It is important that there are safeguards to ensure that products containing biocides can be used without causing harm to people, the environment or animals. This process is governed by national and international governing organizations, such as:

- In the UK, Health and Safety Executive (HSE) is the UK Authority for biocides that runs two regulatory schemes ${ }^{4}$, which assess the safety of such products and the active substances within them, and puts conditions on the use of these products.

- In the European Union, Biocides Regulation (Regulation $528 / 2012$ ) covers a very diverse group of products. It repeals and updates the Biocidal Products Directive 98/8/EEC.

- In the USA, the Federal Aviation Administration (FAA) that has published a Special Airworthiness Information Bulletin (SAIB), which provides general guidance on the use of biocide jet fuel additives that can be used to supplement existing original equipment manufacturer procedures.

The two most common biocides in use for the decontamination in aviation industry are Biobor JF and Kathon FP1.5.

\section{Biobor JF}

Biobor JF5 is a liquid fuel additive developed in 1965 to combat fungus and other microbial life in hydrocarbon fuels such as home heating, diesel, jet fuels, and light oils. It eliminates growth of harmful slime-producing fungi and algae that clog filters and fuel lines, attack rubber fuel system components and whose waste products aid in the corrosion of metal surfaces. Biobor JF is easy to use and harmless to the wide variety of fuel system parts, top coatings, sealants and elastomeric materials used. Some of the physical and chemical properties of Biobor JF are shown in the table below (Table 1).

Table 1: Physical and chemical properties of Biobor JF.

\begin{tabular}{|c|c|}
\hline Property & Description \\
\hline $\mathrm{pH}$ & Not Applicable \\
\hline Odour & Aromatic \\
\hline Evaporation rate & $<1(\mathrm{n}$-Butyl Alcohol $)$ \\
\hline Flash point & $102^{\circ} \mathrm{F}\left(38.8^{\circ} \mathrm{C}\right)$ \\
\hline Appearance & $\mathrm{Clear}^{\circ}$ liquid \\
\hline Boiling point & $529^{\circ} \mathrm{F}\left(276.1^{\circ} \mathrm{C}\right)$ \\
\hline Specific gravity & 1.05 \\
\hline Hazard class & Hazardous as a flammable liquid \\
\hline
\end{tabular}

\section{Kathon FP 1.5}

Kathon FP 1.5 is biocidal substance that has been notified under the Biocidal Products Directive (BPD) and is registered with the United States Environmental Protection Agency (US EPA). It is a solution of the technical grade of the active ingredient, CMIT/MIT ${ }^{6}$, in dipropylene glycol at a nominal value of $1.5 \%$ of active substance. Kathon FP 1.5 is effective against microbial species commonly encountered in fuel systems, including bacteria, yeast, and mould. It is designed to cause inhibition that rapidly becomes irreversible and results in cell death of microbial growth upon contact.

For fuels that are heavily contaminated, Kathon FP 1.5 is used as a shock biocide. In these cases, doses up to 1000 particles per million (ppm $)^{7}$ can be administered according to the BPD. In this case, the residence time is recommended to be a full 24 hours.

\footnotetext{
${ }^{4}$ These schemes are: the Biocidal Products Regulations and the Control of Pesticides Regulations.

${ }^{5}$ In 1965 scientist and engineers from U.S. Borax and SOHIO created the first aviation fuel biocide and named it Biobor JF ${ }^{\circledR}$

${ }^{6}$ Abbreviated name for KATHON ${ }^{\top M}$ FP 1.5 contains a 3:1 ratio mixture of 5-chloro-2-methyl-(2H)isothiazolone (CMIT) and 2-methyl-3(2H)isothiazolone (MIT).

${ }^{7} 1$ litre of biocide per 1000 liters of aviation fuel.
} 
Kathon FP 1.5 can also be used in fuels not contaminated with microbial, as a preventative maintenance measure (to guard against bacterial contamination). In those cases, the recommended dosage is 100 to $150 \mathrm{ppm}$. The biocide should be added in such a manner so as to allow good mixing and uniform distribution of the biocide across the fuel. In such a case the residence time should be at least 12 hours (Table 2).

Table 2: Physical \& chemical properties of Kathon FP1.5.

\begin{tabular}{|c|c|}
\hline Property & Description \\
\hline $\mathrm{pH}$ & 6 -Apr \\
\hline Odour & Mild \\
\hline Appearance & Yellow, liquid \\
\hline Molecular weight $(\mathrm{g} / \mathrm{mol})$ & $149.45(\mathrm{CMIT}), 115.16(\mathrm{MIT})$ \\
\hline Freezing point & $<-20^{\circ} \mathrm{C}\left(-4^{\circ} \mathrm{F}\right)$ \\
\hline Specific gravity & 1.04 \\
\hline Hazard Class & Corrosive material \\
\hline
\end{tabular}

DuPont, the manufacturer of Kathon FP1.5 announced in March 2020 that they are no longer able to sell it for aviation fuel applications, but many other users, from rail operators to superyachts, could use it.

\section{MIRCE Science Analysis of "a serious incident" of G-POWN Aircraft}

This case study focuses on MIRCE Science analysis of functionability event related to the microbial decontamination of aircraft G-POWN in February of 2020 with objectives to understand actions that led to the occurrence of this negative functionability event, as well as to derived the actions that should be taken in the future for the reduction of the probability of their re-occurrences.

\section{The Aircraft (G-POWN)}

The aircraft considered, Airbus A321-211, originated the motion through MIRCE Space in March 2009 as OE-LET in Austria, as a part of Niki Airways fleet. It was equipped with a two SFMI ${ }^{8}$ engines. In March 2016 it was purchased by Titan Airways, a passenger and cargo air-charter services company in UK and continued in-service life as G-POWN. During its motion through MIRCE Space G-POWN was scheduled to enter a NFS in late January 2020 for an extensive positive functionability action with an Approved Maintenance Organisation (AMO). As a pre-requisite for this PFA, on 23 November 2019 the operator took fuel samples from the aircraft tanks to be tested for microbial contamination ${ }^{9}$, in accordance with the Aircraft Maintenance Manual (AMM). The samples were sent to a laboratory which determined a moderate level of contamination. The AMM's report states that a second test is required no more than 10 days after the first test and, should this show positive, then biocidal treatment should be applied to the fuel tanks within a further 10 days. A work card for the treatment of the tanks was raised by the operator and sent to the AMO on 8 January 2020 for inclusion in the scheduled PFA. No further microbiological testing was performed.

\section{The scheduled positive functionability action}

The aircraft entered the AMO's hangar on 23 January 2020 and the PFA started. The operator's work card requested a biocidal shock treatment for moderate contamination with Kathon FP1.5 biocide in accordance with AMM Task 28-11-00-600-008-A01. The biocidal treatment was not designated a critical maintenance task ${ }^{10}$ by the AMO. The task states that fuel should be mixed with Kathon biocide at a concentration of 100 parts per million (ppm) by volume and then the aircraft pressure-refuelled using the onboard automatic control functionality in accordance with AMM Task 1211-28-650-003-A ${ }^{11}$. The Kathon dosed fuel should remain in the aircraft fuel tanks for 24 hours.

The EASA Part-66 B1 licensed AMO engineer dealing with this task was not familiar with the term 'ppm'. It was not written in expanded form anywhere in the AMM Task or glossary, and the AMM task did not provide instructions about how to perform the calculation of the quantity of Kathon to be use. The engineer searched the Internet for a definition and conversion calculator. Knowing that each wing tank contains $6,200 \mathrm{~kg}$ of fuel, based on Internet calculator, he calculated that a quantity of $30 \mathrm{~kg}$ of Kathon should be added to each wing tank.

The AMO engineer added $30 \mathrm{~kg}$ of Kathon to each wing tank through the overwing apertures and uplifted 6,200 $\mathrm{kg}$ of fuel into both wing tanks. In accordance with the AMM task, the engine and APU fuel filters where changed and aircraft was left in situ for 24 hours. The next day 6,400 kg of fuel was transferred from the wing tanks to the center fuel tank and again left in situ for 24 hours. All the access panels to the fuel tanks were open to allow work to be carried inside them until 19 February 2020 when the aircraft was moved outside. Once outside, the fuel tanks were leak-checked and treated for moderate microbial contamination. Finally, the task card was stamped as complete, with a further task opened to perform a biological contamination check within 10 days, but after at least 5 flights. The aircraft departed the AMO in PFS and returned to the operator's base on 24 February 2020.

\footnotetext{
${ }^{8}$ French-American high-bypass turbofan aircraft engine made by CMF International (CFMI), which is 50-50 joint-owned company of Safran Aircraft Engines (formerly known as Snecma) of France and General Electric (GE) of the United States.

${ }^{9}$ Task 12-32-28-281-003-A, Sample Fuel for Microbiological Contamination Analysis.

${ }^{10}$ EASA Part M, AMC1 M.A.402(h) Performance of CRITICAL MAINTENANCE TASKS. https://www.easa.europa.eu/sites/default/files/dfu/Annex\%20 I\%20to\%20Decision\%202016-011-R.pdf (accessed 07 April 2020)

${ }^{11}$ Pressure Refuel with Automatic Control
} 


\section{The negative functionability event on 26 February 2020}

At 2349 hrs G-POWN's crew of initiated a positioning ${ }^{12}$ flight from London Gatwick Airport (Gatwick) to London Stansted Airport (Stansted), by starting the No 2 engine, but they experienced difficulties starting the No 1. Technical Control suggested to pilot to attempt another start, which was successful. As the engine control indications appeared normal, the crew commenced the takeoff at $0009 \mathrm{hrs}$. At around $500 \mathrm{ft}$, the No 1 engine began banging and surging. Pilot observed that the engine's control indications were fluctuating, and the aircraft was "yawing... and fishtailing... all over the place" [3]. However, there was no accompanying message from the Electronic Centralised Aircraft Monitoring (ECAM) system. A number of cabin crew saw flames coming from the No 1 engine's tailpipe and attempted to contact flight crew via the interphone. Flying pilot transmitted a MAYDAY call, requesting a return and issued an alert call to the cabin crew. Just after commencing descent, the ECAM message "Eng 2 stall" was displayed three times in quick succession. Co-pilot prepared the aircraft's flight management guidance system for a return and the pilot positioned the aircraft on a $9 \mathrm{~nm}$ final approach. He opted to fly slightly above the glide path in order to minimise the thrust required by the engines, and so that he could glide the aircraft to the runway if the engine problems worsened. The aircraft landed at $0020 \mathrm{hrs}$, with the reverse thrust appearing to function normally [3]. The Air Accident Investigation Branch (AAIB) of the UK Government classified this NFE as "a serious incident" and began an investigation on 26 February 2020 in accordance with established international arrangements ${ }^{13}$.

\section{Sequence of functionability events preceding the incident flight}

On 26 February 2020, G-POWN's first job was a positioning flight from Stansted to Gatwick. At around $0520 \mathrm{hrs}$, the No 2 engine started normally, but the flight crew experienced problems while starting the No 1 . The engineer who was assisting with the engine starts, via an external headset, advised the crew to attempt another start on the No 1 engine, which was successful.

Later in the day, a different crew boarded G-POWN to conduct a return charter trip to Krakow International Airport (Krakow), Poland. The engines operated normally on the outbound flight. At around $2000 \mathrm{hrs}$, at the beginning of the return flight the No 1 engine required more than one attempt to start successfully. The crew notified the operator of the starting problem via a datalink ${ }^{14}$ message from the aircraft after departure from Krakow. During the flight, the ECAM system displayed the message "Eng 2 stall" momentarily on two occasions. On arrival at Gatwick, at around $2230 \mathrm{hrs}$, the pilot informed the operator's Technical Control department via phone that the No 2 engine stall event and the defect was recorded in G-POWN's technical log [3].

The operator's Technical Control instructed an EASA Part-66 B1 licensed engineer, who worked for an EASA Part-145 AMO that provided line maintenance at Gatwick for the operator, to attend the aircraft to troubleshoot the No 2 engine stall. The engineer accessed the troubleshooting manual (TSM) via manufacturer's online system AIRBUS World: AirN@v Maintenance. This system had two different applications: AirN@v and airnavX that was recently introduced to replace AirN@v. The operator had granted the AMO access to the operator's data on AirN@v but not airnavX, so the engineer used AirN@v to try and access the applicable troubleshooting procedure. The design of airnavX requires the user to filter data to a specific aircraft before going through the troubleshooting process but AirN@v does not. The engineer did not filter the TSM for the G-POWN, but accessed the procedure using the TSM table of contents, which enabled him to access the procedures for all the operator's Airbus aircraft. Consequently, the engineer printed and followed TSM procedure 77-11-00-810-815$\mathrm{A}^{15}$, which applied to LEAP-1A32 engines.

However, G-POWN was fitted with the CFM56-5B3/3 engine and the applicable TSM procedure for this engine is 73-00-00-810866- $\mathrm{A}^{16}$, which requires an extensive examination of the engine, including borescope inspections of the high pressure and Stage 1 low-pressure turbine blades. As the no fault was found during the troubleshooting procedure, the engineer signed off the engine stall defect and the Certificate of Release to Service in G-POWN's technical log.

\section{Post incident functionability analysis}

In order to understand the mechanisms that generated this "serious incident" several analysis are performed, some of which are briefly presented below.

\section{Fuel analysis}

Fuel samples were taken from both wing fuel tanks, and water drain valves were subjected to laboratory analysis. The tested fuel was found not to comply with the JET A-1 specification requirements ${ }^{17}$ for appearance and water separation

\footnotetext{
${ }^{12}$ Positioning flight - a flight without passengers

${ }^{13}$ The AAIB is being assisted by Accredited Representatives appointed by the Bureau d'Enquêtes et d'Analyses pour la Sécurité de l'Aviation Civile in France, the National Transportation Safety Board in the USA, and the Aircraft Accident and Incident Investigation Board in Cyprus. The Accredited Representatives are supported by Technical Advisors from the aircraft and engine manufacturers.

${ }^{14}$ Datalink - A system of text messaging between aircraft and ground stations

${ }^{15}$ Stall above idle on engine $1(2)$

${ }^{16}$ Stall of engine 1 or 2 in flight

${ }^{17}$ EF STAN 91-091 Issue 11 and AFQRJOS Check List Issue 31.
} 
characteristics. The fuel samples, once the contents had settled out under gravity, contained a separate brown liquid layer beneath the main fuel layer. Trace element results of the fuel and the bottom brown layer showed similar spectra to a reference Kathon sample, but with a higher water content. The laboratory that conducted the fuel testing concluded that [3]: "The results indicate contamination with undissolved Kathon. It was noted that the bottom layer that is mostly Kathon plus some unknown products and water, suspected to be causing the darker colour than the reference Kathon sample. This is likely due to the glycol type solvent used in Kathon product dissolving polar materials from the fuel and fuel tank surfaces."

\section{Engines analysis}

The aircraft's engines were examined visually using a borescope and both exhibited the following findings: "There was no significant damage evident to the fan, low-pressure compressor or high-pressure compressor components, and any minor defects that were identified were within AMM damage limits. The combustion chambers, high-pressure and low-pressure turbine blades were coated in a thin layer of white material that was observed on the turbine blades' convex surfaces. The high-pressure turbine nozzle guide vanes were also coated in the white material" [3].

The borescope inspections performed was unable to collect samples of the white and brown materials from within the engines at the time. Additional examinations are planned that will include inspection of the engines' fuel system components. 14-17

\section{Kathon FP1.5 quantity analysis}

The AMO engineer who determined the amount of Kathon to be added to the aviation fuel had never performed that task before and did not recognise that the computer assisted calculation was approximately 37 times higher that the recommended dose. To achieve a concentration of $100 \mathrm{ppm}$ by volume, the following calculation should be made: $6,200 \mathrm{~kg}$ of aviation fuel uplifted, with a Specific Gravity ${ }^{18}$ of 0.8075 (average) equates to 7,678 litres. For the recommended concentration of $100 \mathrm{ppm}$ the correct amount of Kathon to be added is equal to 7,678 $0.0001=0.7678$ litres. Using a Kathon Specific Gravity of 1.04 (see table 2) the amount that should be added is $0.7985 \mathrm{~kg}$ per wing tank.

Hence, the amount of Kathon added was approximately 37 times greater that the amount recommended. As the manufacturer of the aircraft had not designated this task as a critical task, no additional measures were used to check that it was performed in accordance with the AMM Task.

\section{Aircraft maintenance organisation analysis}

According to AAIB [3] the total amount of Kathon available in the AMO stores at Gatwick was $150 \mathrm{~kg}$. However, there was no "alarm bell ringing" when the mechanic working on G-POWN made a material requisition for $60 \mathrm{~kg}$ of Kathon.

It appears that no control measures were in place at the AMO stores or planning departments to prevent unusually large quantities of chemicals being issued to AMO staff.

\section{Aircraft maintenance manual analysis}

The AMM task instructions used the term 'ppm' for which there was no definition within the AMM glossary, and even more, no guidance was provided for the calculation of biocide fuel dosing calculation.

\section{Troubleshooting task}

During the three flights on 26 February G-POWN experienced the following two problems:

- difficulties with the start-up of No 1 engine at Stanstead and Krakow

- $\quad$ momentary "Eng 2 stall" messages associated with the No 2 engine on descent into Gatwick.

However, the engineer allocated to deal with G-POWN that evening was tasked with troubleshooting the engine No 2 stall messages.

This was a lost opportunity to detect the abnormal deposits on the high pressure and low-pressure turbine blades. It is probably likely that a borescope inspection would have detected these deposits and, had it done so, it is unlikely that the aircraft would have been released to service. 18

In summary, the engineer on duty was not tasked with investigating any issues with the No 1 engine. As the symptoms presented by each engine were different no one considered there to be a possible common cause.

\section{Safety Actions Taken After the Incident Event}

Based on the analysis performed several safety related actions have been implemented by regulators and operators. Some of them are briefly addressed below.

\section{Actions by regulators}

The EASA issued Safety Information Bulletin SIB 2020-0616 on 20 March 2020, to notify affected stakeholders of recent air safetyrelated events involving Kathon biocide and to remind aircraft owners and operators to ensure that the correct method and dosage is used for approved biocide treatment of aircraft fuel systems.

The FAA issued Special Airworthiness Information Bulletin SAIB NE-20-04 $4^{19}$ on 25 March 2020 that contained similar regulatory guidance.

\footnotetext{
${ }^{18}$ According to British MoD DEF STAN 91-091 Issue 11 a Specific Gravity of Jet A1 fuel is between 0.775 and 0.84 at $15^{\circ} \mathrm{C}$. Thus, 1 kg of Jet A1 will range for a volume of 1.29 to 1.19 litres.

${ }^{19}$ https://rgl.faa.gov/Regulatory_and_Guidance_Library/rgSAIB.nsf/dc7bd4f27e5f107486257221005f069d/05f721d6c7272c09862585 36005bbe41/\$FILE/NE-20-04_Corrected.pdf (accessed 9 April 2020).
} 


\section{Actions by the manufacturers of the biocide and engines}

- On 10 March 2020 the manufacturer of Kathon discontinued the use of its product for aviation fuel applications.

- On 16 March 2020, CFM, the manufacturer of theG-POWN's engines, issued Alert Service Bulletin 73-A0296 recommending that operators of CFM56-5B engines suspend the use of Kathon during aircraft fuel system biocide treatments.

- Similar instructions were issued for other variants of the CFM56 engine family, as well as all General Electric turbofan engines ${ }^{20}$.

\section{Actions by the AMO at London Gatwick Airport}

The AMO that performed the biocide treatment on G-POWN has introduced a new role of 'technical engineer'. The technical engineer is expected to be an EASA Part-66 B1 licensed engineer, outside of the management chain within the organisation, who will be available to assist other licensed engineers and mechanics with technical queries, such as calculations.

The AMO is also expecting to introduce usage limits in stores so that staff will not be able to withdraw chemicals in quantities that significantly exceed the maximum permitted.

The Gatwick AMO issued a safety and compliance notice highlighting the importance of filtering maintenance data to the specific aircraft when using the TSM via manufacturer's online system AIRBUS World.19,20

\section{Action by the Operator}

In consultation with the manufacturer, the operator granted the Gatwick AMO access to the airnavX system.

\section{Conclusion}

The main objective of this paper is to address microbial decontamination of fuel tanks as a potential mechanism of the motion of an aircraft though MIRCE Space, in accordance to MIRCE Science.

Although in-service problems with this functionability action are not frequent, the consequences of its incorrect execution could lead to the occurrence of " serious incidents", which could have a huge impact on functionability performances, namely work done and resources consumed.

The case study analysed in this paper is related to the microbial decontamination of fuel tanks of Airbus G-POWN that took place at London Gatwick Airport on 26 February 2020. A full analysis of the sequence of functionability actions that led to the occurrence of "a serious incident" presented in this paper is essential for the understanding of the actions that should be taken regarding the reduction of the probability of human errors during the execution of this maintenance task, starting with the design of maintenance task and its description in Aircraft Maintenance Manual to the safety practices within Approved Maintenance Organisations, regarding: training of maintenance personnel, creation of technical engineer and usage limits in stores.

\section{Acknowledgement}

None.

\section{Conflict of Interest}

No conflict of interest.

\section{References}

1. Knezevic J (2017) The Origin of MIRCE Science, MIRCE Science, Exeter, UK, pp 242

2. Knezevic J Microbial Contamination of Fuel Tanks as a Mechanism of the Motion of an Aircraft through MIRCE Space.

3. (2020) Air Accident Investigation Branch (AAIB) Bulletin S1/2020 Airbus A321-211, G-POWN.

\footnotetext{
${ }^{20}$ The discontinuation of Kathon for aviation applications, combined with the inability to use Biobor within the European Union presently, leaves their aircraft operators without an approved biocide treatment.
} 